\title{
EDUCAÇÃO AOS PRIVADOS DE LIBERDADE NO AMAZONAS: correntezas de um direito
}

\author{
Fabiane Maia Garcial \\ Gerusa Moraes de Souza²
}

\section{RESUMO}

O artigo apresenta um conjunto de legislação que ampara a oferta educativa aos privados de liberdade e a produção técnica e científica sobre a temática em discussão no Amazonas. O texto se estrutura a partir dos aspectos históricos da educação no sistema prisional do Amazonas e de um mapeamento nos Programas de Pós-graduação da Universidade Federal do Amazonas (UFAM) e Universidade do Estado do Amazonas (UEA). A base metodológica se amparou na pesquisa documental articulada ao estado da arte da temática, com a opção pela abordagem quantiqualitativa. Na análise e interpretação dos dados foram categorizadas as abordagens, os tipos de pesquisa e os principais resultados em um esforço de tipificar essa modalidade educativa no Amazonas.

Palavras-chave: Educação. Direitos humanos. Privados de liberdade.

\section{EDUCATION TO THE PRIVATE LIBERTY IN THE AMAZON: currencies of a law}

\begin{abstract}
The article proposes to present the set of legislation that protects the educational offer to the deprived of freedom, in the international, national and local scope, besides gathering the references that compose the technical and scientific production on the subject under discussion in the Amazon. The text is structured from the historical aspects of education in the prison system of Amazonas, a mapping of Theses and Dissertations in the Graduate Programs of the Federal University of Amazonas (UFAM) and the State University of Amazonas (UEA). The methodological basis is supported by documentary research articulated to the state of the art of the subject, with the option of the quantiqualitative approach. In the analysis and interpretation of the data contained in the productions within the Programs

\footnotetext{
1 Doutora. Universidade Federal do Amazonas - UFAM, Manaus, Amazonas. Orcid iD: https://orcid.org/0000-0003-0121-0416.E-mail: fgarcia@ufam.edu.br

2 Graduada em Pedagogia e mestranda em educação. Universidade Federal do Amazonas - UFAM, Manaus, Amazonas. Orcid iD: https://orcid.org/0000-0002-2583-6774. E-mail: gerusamoraespj@gmail.com
} 
were categorized the approaches, the types of research and the main results, and finally there was the effort to typify the existing educational offer in the prison system of Amazonas.

Keywords: Education. Human rights. Deprivation of liberty.

\section{LA EDUCACIÓN A LA LIBERTAD PRIVADA EN LA AMAZONÍA: las divisas de una ley}

\section{RESUMEN}

El artículo presenta un conjunto de legislaciones que protegen la oferta educativa a los privados de libertad y la producción técnica y científica sobre el tema en discusión en la Amazonía. El texto está estructurado a partir de los aspectos históricos de la educación en el sistema penitenciario de Amazonas y de un un mapeo en los Programas de Postgrado de la Universidad Federal de Amazonas (UFAM) y la Universidad del Estado de Amazonas (UEA). La base metodológica se basó en la investigación documental articulada al estado del arte de la temática, con la opción del enfoque cuanti-cualitativo. En el análisis e interpretación de los datos se categorizaron los enfoques, los tipos de investigación y los principales resultados en un esfuerzo por tipificar esta modalidad educativa en la Amazonía.

Palabras clave: Educacion. Derechos humanos. Privados de su libertad.

\section{INTRODUÇÃO}

No Amazonas as correntezas caracterizam-se por um curso d'água formando pequenas ondas, tornando-se muitas vezes grandes obstáculos para que os ribeirinhos sigam com suas canoas ou barcos rumo ao seu destino. Utilizamos no título a metáfora "correntezas de um direito" com a pretensão de comparar o processo de efetivação do direito à educação aos privados de liberdade no Amazonas com as correntezas de nossos rios. Assim como a beleza dos rios esconde os perigos das correntezas, existe também na oferta educativa, aos privados de liberdade, um contraste entre o direito garantido nos dispositivos legais com a realidade educativa presente na escola, que funciona no interior do sistema prisional.

A presente pesquisa parte do pressuposto de que em relação à oferta educativa aos privados de liberdade são tímidas as discussões e abordagens 
teóricas do processo educativo tanto na oferta quanto na prática dos docentes. Garcia et al. (2018) destacam que a educação brasileira é marcada por lutas que incluem a oferta da educação no sistema prisional, mas há uma espécie de silenciamento do debate no campo da produção, análise técnica e científica da temática.

O foco do estudo foi a análise das produções técnicas e científicas dos programas de pós-graduação do Amazonas sobre a oferta educativa aos privados de liberdade. Partiu-se, no primeiro momento do levantamento dos aportes legais e políticos que embasam a discussão da oferta educativa no Sistema Prisional no âmbito internacional, nacional e local, tais como: Declaração Universal dos Direitos Humanos (1948); Constituição Federal (CF 1988); Lei de Execução Penal (LEP 1984); Lei nº 12. 433 (LEP 2011); Lei No 13. 163 (LEP 2015); Plano Nacional de Educação em Direitos Humanos (PNEDH 2007); Lei de Diretrizes e Bases da Educação (LDB, 1996); Resolução No 02/2010 que estabelece as Diretrizes Nacionais para oferta de educação aos Privados de Liberdade; Plano Estratégico de Educação no Âmbito do Sistema Prisional (PEESP 2011) e, o Plano Estadual de Educação nas Prisões (PEEP - AM 2012). Buscamos, também, reunir os principais referenciais que se destacam quando se trata da temática em estudo: Mayer (2013); Julião (2018); Cacicedo (2016) e Valois (2013).

Por outro lado, lançou-se mão dos aspectos históricos da oferta educativa aos privados de liberdade no Amazonas à luz do histórico apresentado no PEEP - AM. A coleta de dados foi realizada pelo acesso ao Sistema de Publicação Eletrônica de Teses e Dissertações (TEDE) da Universidade Federal do Amazonas - UFAM e da Universidade do Estado do Amazonas - UEA. Ao fazermos a análise das teses e dissertações, identificadas no TEDE, categorizamos as abordagens, os tipos de pesquisa e os principais resultados dessas produções, para que então, buscássemos tipificar a identidade da educação no sistema prisional do Estado.

Desse modo, a pesquisa analisou a produção técnica e científica da oferta educativa no sistema prisional do Amazonas com a intenção de contribuir para que se conheça como vem sendo abordada a temática nos 
programas de pós-graduação do Estado. Possibilitando, ainda, uma reflexão sobre a ampliação de estudos e sistematizações no meio acadêmico.

\section{APORTES TEÓRICOS E LEGAIS QUE EMBASAM A DISCUSSÃO DA OFERTA EDUCATIVA NO SISTEMA PRISIONAL}

Nos últimos anos a expressão "bandido bom é bandido morto" tornouse bastante discutida nos meios de comunicação, redes sociais e até por alguns formadores de opinião pública. Os direitos concedidos à população privada de liberdade constantemente são alvos de ataques, visto que a sociedade já condena o privado de liberdade antes mesmo de ser sentenciado pela justiça. Há quem defenda que as pessoas privadas de liberdade devem ser isentas de direitos e que os Direitos Humanos são somente para "Humanos Direitos", que a pessoa que teve uma má conduta não deve ser "beneficiada".

No entanto, o entendimento aqui evocado reforça a ideia dos Direitos Humanos, como o próprio termo sugere, destinados para todos os humanos, sem distinção de etnia, cor, sexo, língua, religião, opinião, origem, riqueza, privados ou não de liberdade ou qualquer outra condição. A única condição exigida para que se goze desses direitos é nossa própria existência. Aos privados de liberdade são vedados os direitos de ir e vir e os direitos políticos, mas não seus direitos sociais básicos previstos no artigo $6^{\circ} \mathrm{da}$ Constituição Federal: "a educação, a saúde, a alimentação, o trabalho, a moradia, o transporte, o lazer, a segurança, a previdência social, a proteção a maternidade a infância, a assistência aos desamparados" (Brasil, 1988).

A concepção de prisão esteve diretamente relacionada ao castigo, e o local em que os presos eram (são) inseridos, esteve relacionado com um local tenebroso e um espaço de sofrimento. Para Valois (2009), a visão prevalente na concepção inicial de cárcere é a ideia de que o culpado tem que sofrer fisicamente em virtude da falta cometida, o quanto mais ele sofresse mais estaria pagando pelo que cometeu. Para além do sofrimento e castigo, podemos acrescer a ideia de isolamento e afastamento daquele que a sociedade julga infrator de suas normas. Contudo, o crescimento da 
população carcerária tem aproximado e "incomodado" a população em livre, cerceando parte de sua liberdade em razão dos muitos problemas que o sistema prisional tem apresentado no Brasil.

Além do crescimento da população carcerária no Brasil, há também uma diversidade de crimes sendo praticados. Assim, o Conselho Nacional de Justiça divulgou, no dia 6 de agosto de 2018, os dados da primeira etapa de implantação do Banco Nacional de Monitoramento de Prisões (BNMP 2.0), cujo objetivo é fazer o mapeamento da população carcerária brasileira a partir de informações do Poder Judiciário. Os dados revelam que em relação aos

tipos

crimes

Tipos Penais mais Recorrentes

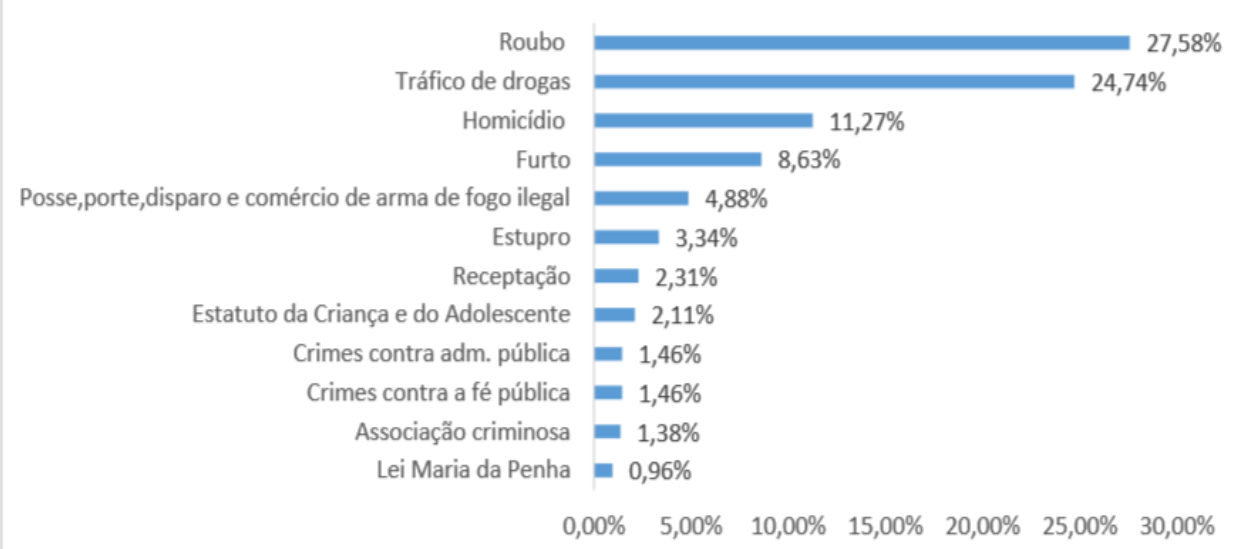

de

imputados às pessoas privadas de liberdade no Brasil, os crimes mais recorrentes são o roubo e o tráfico de drogas. Conforme mostra o gráfico abaixo:

\section{Gráfico 1. Tipos de crimes mais recorrentes no Brasil}


Fonte: BNMP 2.0/CNJ - 6 de agosto de 2018

Como descrito por Foucault (2009, p. 9), "[...] os grandes delinquentes, os grandes criminosos, não representam $5 \%$ do conjunto dos prisioneiros. $O$ resto é a delinquência média e pequena. Essencialmente, pessoas de classes pobres". Os dados apontam, ainda, que em relação à faixa etária dos privados de liberdade3:

Gráfico 2. Faixa etária das pessoas privadas de liberdade no Brasil

Fonte: BNMP 2.0/CNJ - 6 de agosto de 2018.

Quando se trata de escolaridade os dados demostram que a maioria dos privados de liberdade não possui o ensino médio completo, como demostrado no gráfico abaixo:

Gráfico 3. Nível de escolaridade das pessoas presas no Brasil

3 Segundo o Conselho Nacional de Justiça (CNJ), a informação disponível refere-se a 543.267 registros que representam $90,21 \%$ do total de pessoas cadastradas no sistema. 
Fonte: BNMP -6 de agosto 2018.
Escolaridade

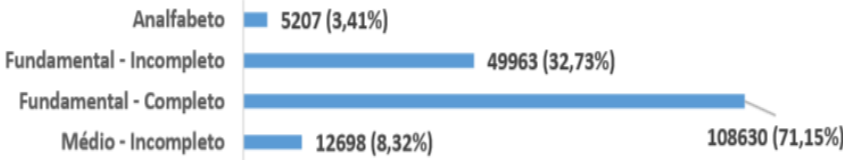

Médio-Completo $28508(18,67 \%)$

Superior - Incompleto I $953(0,62 \%)$

Superior - Completo | $1724(1,13 \%)$

Pós-graduação (lato sensu) - Incompleto $132(0,09 \%)$

Pós-graduação (lato sensu) - Completo $25(0,02 \%)$

Pós-graduação (stricto sensu, nível mestrado) - Incompleto $\quad 1(0,001 \%)$

Pós-graduação (stricto sensu, nivel mestrado) - Completo $2(0,001 \%)$
2.0/CNJ de

Diante das informações acima, divulgadas pelo Conselho Nacional de Justiça (CNJ 2018), percebe-se que a população privada de liberdade é formada predominantemente por jovens, pobres e de baixa escolaridade. Como afirma Maeyer (2013):

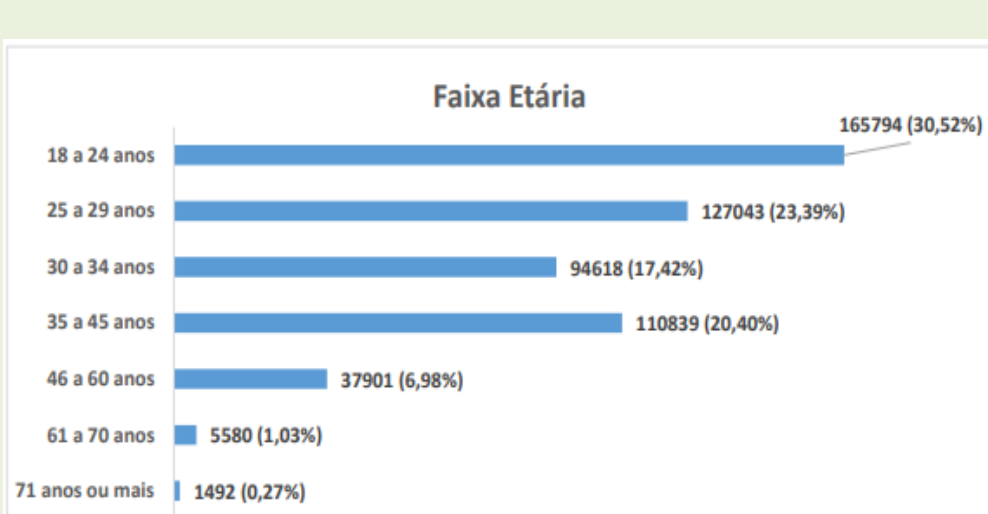

A maior parte dos detentos é constituída por pobres, tem um nível educacional muito baixo, jamais conheceram a escola ou, quando conheceram, sua experiência frequentemente terminou em fracasso: muitos detentos são jovens ainda e, em numerosos países, os migrantes (econômicos) constituem uma parte importante da população carcerária (MAYER, 2013, p.35).

A população prisional antes de ser privada de liberdade, foi privada de direitos básicos, tais como a alimentação, saúde, educação e trabalho. Marx (2006, p. 06) afirma que "os homens fazem a sua própria história, mas não a fazem segundo a sua livre vontade". A educação é a base para que todas as outras coisas aconteçam, como evidencia o artigo 205 da Constituição Federal de 1988: 
A educação, direito de todos e dever do Estado e da família, será promovida e incentivada com a colaboração da sociedade, visando ao pleno desenvolvimento da pessoa, seu preparo para o exercício da cidadania e sua qualificação para o trabalho (Brasil, 1988).

A Declaração Universal dos Direitos Humanos, adotada e proclamada pela Assembleia Geral das Nações Unidas (Resolução 217 A III) em 10 de dezembro de 1948, determina, em seu artigo 27, "que todo o ser humano tem direito à instrução". Mais tarde, em 1988, a Constituição Federal (CF), no artigo 205, reconhece a educação como um direito de todos sob responsabilidade do Estado e da família. E reitera, no artigo 208, VII, $\S 1^{\circ}$, que o acesso ao ensino público e gratuito é um direito público subjetivo, entendido como um direito inalienável, o qual não pode ser negado a nenhuma pessoa, seja ela provida ou desprovida de liberdade.

Nesse sentido é importante destacar que a educação oferecida no sistema prisional é um direito e não um benefício, o qual muitas vezes é confundida. Valois $(2013$, p. 1) afirma que "[...] chamar direito do cidadão preso, ou de quem quer que seja, de benefício é diminuir, dificultar e não raramente obstaculizar esse direito".

A Lei de Execução Penal (LEP 1984), no artigo 10, atribui ao Estado a responsabilidade em oferecer assistência ao preso, cujo objetivo é prevenir o crime e orientar o detento para o retorno em convivência social. As formas de assistência ${ }^{4}$ aos presos, de acordo com o artigo 11 da LEP, são: material, saúde, jurídica, educacional e religiosa. $\mathrm{O}$ art. 17 da referida lei assegura que a assistência educacional aos detentos compreenderá a instrução escolar e a formação profissional do preso e do internado.

A Lei $n^{\circ}$ 12. 433, de 29 de junho de 2011 , altera a LEP no qual dispõe sobre a remição da pena por estudo ou por trabalho. Nesse sentido o artigo 126 determina que: "O condenado que cumpre a pena em regime fechado

\footnotetext{
${ }^{4}$ Todavia, Cacicedo (2016) faz uma crítica a utilização do termo "assistência" pois segundo o autor a CF 88 "eleva a educação nas prisões a um patamar de direito fundamental, que supera o caráter de mera assistência educacional, como previsto nos artigos 17 e seguintes da Lei de Execução Penal de 1984 (2016, p.125)".
} 
ou semiaberto poderá remir, por trabalho ou por estudo, parte do tempo de execução da pena" (Brasil, 2011). Assim:

$\S 1^{\circ}$ A contagem de tempo referida no caput será feita à razão de: I - 1 (um) dia de pena a cada 12 (doze) horas de frequência escolar atividade de ensino fundamental, médio, inclusive profissionalizante, ou superior, ou ainda de requalificação profissional - divididas, no mínimo, em 3 (três) dias;

II - 1 (um) dia de pena a cada 3 (três) dias de trabalho (Brasil, 2011).

No dia 09 de setembro de 2015 foi sancionada, pelo Congresso Nacional, a Lei No 13.163, que Modifica a Lei no 7.210 (Lei de Execução Penal), de 11 de julho de 1984, e torna obrigatório o ensino médio nos presídios. Com essa modificação, tanto o ensino fundamental como o ensino médio deverá ser obrigatoriamente oferecido aos detentos.

A Educação de Jovens e Adultos (EJA) é a modalidade de educação oferecida aos Privados de Liberdade, como previsto no art. 37 da Lei $N^{\circ}$ 9394/1996, Lei de Diretrizes e Bases da Educação Nacional (LDB, 1996). No qual afirma que "será destinada àqueles que não tiveram acesso ou continuidade de estudos nos ensinos fundamental e médio na idade própria e constituirá instrumento para a educação e a aprendizagem ao longo da vida (Brasil, 1996)".

O Estado brasileiro possui o Plano Nacional de Educação em Direitos Humanos (PNEDH, 2007), o qual [...] é fruto do compromisso do Estado com a concretização dos direitos humanos e de uma construção histórica da sociedade civil organizada (BRASIL, 2007, p. 11). O PNEDH, pautado em aspectos dos principais documentos internacionais de direitos humanos, estabelece concepções, princípios, objetivos, diretrizes e linhas de ação a fim de que seja efetivada a democracia, o desenvolvimento, a justiça social e a construção de uma cultura de paz. E quando se trata da oferta educativa aos Privados de Liberdade, o referido Plano define, no item I denominado "Educação Básica", como ação programática:

Promover e garantir a elaboração e a implementação de programas educativos que assegurem, no sistema penitenciário, processos de 
formação na perspectiva crítica dos direitos humanos, com a inclusão de atividades profissionalizantes, artísticas, esportivas e de lazer para a população prisional (BRASIL, 2007, p. 34).

O PNEDH (2007, p. 51) pactua ainda, como ação programática no item IV intitulado "Educação dos Profissionais dos Sistemas de Justiça e Segurança", ação 13 "incentivar o desenvolvimento de programas e projetos de educação em direitos humanos nas penitenciárias e demais órgãos do sistema prisional, inclusive nas delegacias e manicômios judiciários". Entretanto, Julião (2016) ressalta que:

Espera-se que os estados, através das suas secretarias estaduais de educação, assumam a política de educação para jovens e adultos em situação de privação de liberdade, reconhecendo-a não mais como uma ação pontual, isolada, voluntária, mas sim como uma política pública de educação (JULIÃO, 2016, p. 28).

A Resolução No 2, de 19 de maio de 2010 do Conselho Nacional de Educação (CNE) e da Câmara de Educação Básica (CEB) estabelece as Diretrizes Nacionais para a oferta de Educação para Jovens e Adultos em situação de privação de liberdade nos estabelecimentos penais. Dentre as regras estabelecidas, pelas Diretrizes, destacamos, em seu art. 4, inciso I, a atribuição dos órgãos responsáveis, nos Estados e no Distrito Federal em tornar público, por meio de relatório anual, a situação e as ações realizadas para a oferta de Educação de Jovens e Adultos, em cada estabelecimento penal.

O Decreto $N^{\circ}$ 7.626, de 24 de novembro de 2011 institui o Plano Estratégico de Educação no âmbito do Sistema Prisional (PEESP), atribuindo ao Ministério da Justiça e da Educação a responsabilidade em coordenar e executar o presente plano. No artigo $6^{\circ}$ e $7^{\circ}$ do PEESP são especificadas as incumbências do Ministério da Justiça e da Educação em relação a oferta da educação no sistema prisional:

Art. $6^{\circ}$ Compete ao Ministério da Educação, na execução do PEESP: I - equipar e aparelhar os espaços destinados às atividades educacionais nos estabelecimentos penais;

II - promover a distribuição de livros didáticos e a composição de acervos de bibliotecas nos estabelecimentos penais; 
III - fomentar a oferta de programas de alfabetização e de educação de jovens e adultos nos estabelecimentos penais; e IV - promover a capacitação de professores e profissionais da educação que atuam na educação em estabelecimentos penais.

Art. $7^{\circ}$ Compete ao Ministério da Justiça, na execução do PEESP:

I - conceder apoio financeiro para construção, ampliação e reforma dos espaços destinados à educação nos estabelecimentos penais;

II - orientar os gestores do sistema prisional para a importância da oferta de educação nos estabelecimentos penais; e

III - realizar o acompanhamento dos indicadores estatísticos do PEESP, por meio de sistema informatizado, visando à orientação das políticas públicas voltadas para o sistema Prisional (BRASIL, 2011).

O PEESP é um documento que detalha como deverá ser a oferta de educação aos Privados de Liberdade, traz ainda as principais competências delegadas aos responsáveis pela Educação no Sistema Prisional.

No âmbito estadual temos no Amazonas o Plano Estadual de Educação nas Prisões (PEEP - AM, 2012), elaborado a fim de obter apoio financeiro para ampliação e qualificação da oferta de educação nos estabelecimentos penais, nos exercícios de 2012, 2013 e 2014. O PEEP - AM específica o trabalho pedagógico realizado dentro do sistema prisional fornecendo informações como: o diagnóstico das Unidades Prisionais, caracterização, histórico, dinâmica pedagógica, procedimentos de rotina, Planos de Ação e Práticas Pedagógicas.

O PEEP - AM ressalta que até 2014 não se tinha regulamentado as Diretrizes Estaduais de educação nas prisões e que a discussão estava no âmbito da Câmara de Educação Básica (AMAZONAS, 2012, p. 57). Garcia, Araújo e Santos (2018, p. 207) afirmam que:

Em virtude de averiguações "desiguais", apontadas pelo MEC no documento redigido no final de 2014, a sugestão sofreu correções e aguarda homologação definitiva do órgão federal. Dada esta justificativa, o Plano Estadual de Educação nas Prisões não estava vigendo até 2017.

As autoras afirmam ainda que as atividades desenvolvidas na Unidade Prisional Semiaberto Feminino (UPSF) prosseguiam com os mesmos modelos da Educação de Jovens e Adultos.

\section{ASPECTOS HISTÓRICOS DA EDUCAÇÃO NO SISTEMA PRISIONAL DO AMAZONAS}


Acredita-se, segundo o Plano Estadual de Educação no Amazonas (PEEP - 2012), que a oferta educativa no Amazonas seja a mais antiga dentro do sistema penitenciário do Brasil, tendo uma caminhada de 90 anos.

O PEEP - AM (2012), no item 3, intitulado "História da Educação nas Prisões do Estado", narra que a primeira experiência de educação nas prisões do Estado do Amazonas teve início no século XX com a criação da Escola Agnello Bittencourt, por meio do Decreto $N^{\circ} 173$, de 12 de maio de 1928. A referida escola estava instalada na Casa de Detenção de Manaus, sendo dirigida pelo capitão José Marques Galvão, estando situada na Avenida Sete de Setembro.

A escola Agnello Bittencourt tinha como objetivo "alfabetizar os presos e esses eram obrigados a frequentar e prosseguir os estudos até o ensino primário completo, conforme aplicação e aproveitamento" (Amazonas, 2012 , p.15). A designação dada ao local em que estava instalada a escola Agnelo Bittencourt sofreu inúmeras modificações. Em 1928, com uma lei sancionada pelo Presidente Ephigenio Ferreira Salles, passou a ser chamada de Casa de Detenção de Manaus. No entanto, em 1942 foi modificado, passando a ser chamada de Penitenciária Central do Estado, mas o governador daquela época, José Bernardino Lindoso, sancionou Lei n 1478 de 03 de dezembro de 1981, passando a ser denominada de Unidade Prisional Central (UPRICENTRO). Em 1985, no mandato do então Governador Gilberto Mestrinho de Medeiros Raposo, foi sancionada a Lei $n^{\circ} 1694$, de 15 de julho de 1985, na qual a Unidade Prisional Central passou a ser intitulada de Penitenciária Desembargador Raimundo Vidal Pessoa, o que perdurou até 1999.

Em decorrência da inauguração do Regime Fechado do Complexo Penitenciário Anísio Jobim, a Penitenciária Desembargador Raimundo Vidal Pessoa passou a ser designada de Cadeia Pública Desembargador Raimundo Vidal Pessoa, passando a abrigar presos provisórios que aguardavam julgamento. Durante o terceiro mandato do Governador do Estado do Amazonas, Gilberto Mestrinho de Medeiros Raposo, a então Escola Estadual da Penitenciária Central do Estado, como era registrada na 
SEDUC, passou a ser nominada de Escola Estadual Giovanni Figliuolo, através do Decreto número 15.250, de 16 de fevereiro de 1993.

A Escola Giovanni Figliuolo tem como patrono o Bacharel em direito pela Universidade Federal do Amazonas - UFAM, Giovanni Figliuolo natural de Belém - PA, que foi Diretor Técnico da Penitenciária Central do Estado do Amazonas. A referida escola oferta Educação de Jovens e Adultos nas etapas do Ensino fundamental e médio, no qual está integrada em 10 anexos que estão distribuídos nas seguintes Unidades Prisionais:

Tabela 1. Oferta educativa em Manaus TURMAS QUE INTEGRAM A ESCOLA GIOVANNI FIGLIUOLO

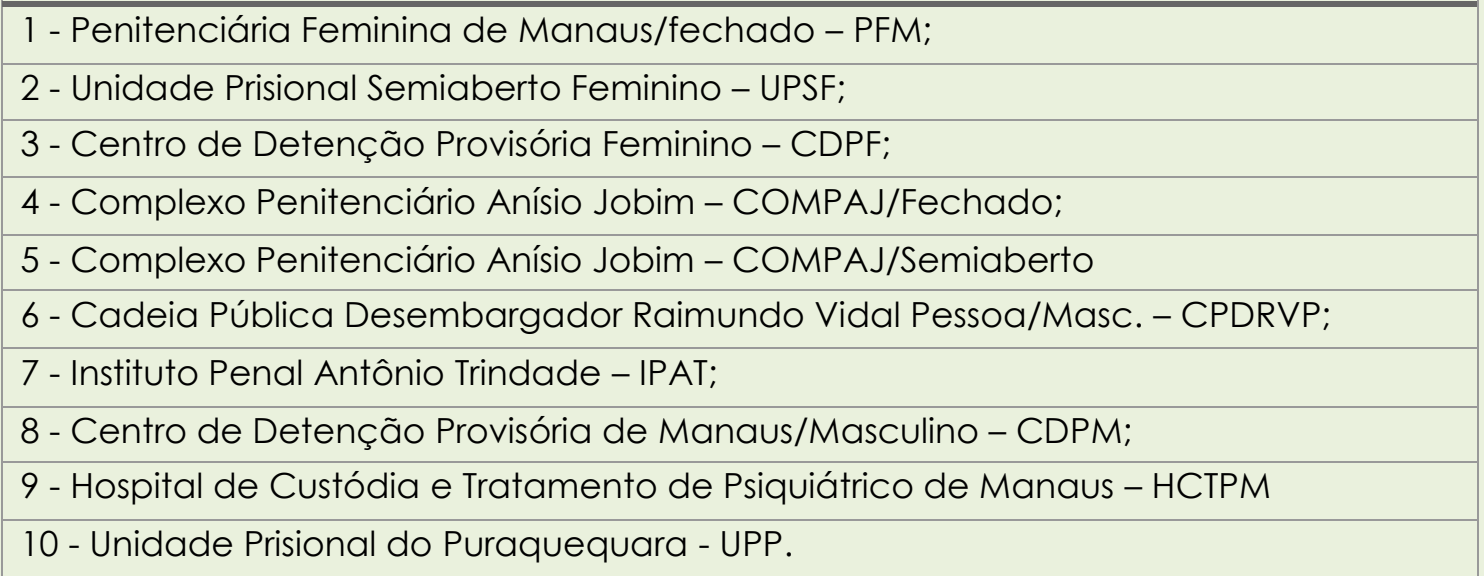

Fonte: elaborada pelas pesquisadoras.

O Estado do Amazonas é composto por 62 (sessenta e dois) municípios, mas, apenas 09 (nove) possuem Unidades Prisionais, nas quais 07 (sete) possuem escolas. São eles:

Tabela 2 - Oferta educativa nos Municípios do Amazonas

\begin{tabular}{|l|}
\hline \multicolumn{1}{|c|}{ UNIDADES PRISIONAIS DO AMAZONAS QUE POSSUEM ESCOLAS } \\
\hline 1 - Coari - Escola Estadual Iraci Leitão; \\
\hline 2- Humaitá - Escola Estadual Profa Marly de Carvalho Lobato Nery; \\
\hline - Itacoatiara - Escola Eng ${ }^{\circ}$ Cassiano Secundo; \\
\hline - Manacapuru - Escola Estadual Regina Fernandes; \\
\hline 5- Manaus - Escola Estadual Giovanni Figlioulo (09 anexos); \\
\hline 6- Parintins - Escola Municipal Vitório Barbosa; \\
\hline 7 - Tabatinga - Escola Estadual Pedro Teixeira. \\
\hline
\end{tabular}

Fonte: elaborada pelas pesquisadoras. 
A situação dos presídios do norte do país é extremamente crítica. As rebeliões que aconteceram em 2017 refletem a precariedade das prisões da região. No Amazonas, no dia 01 e 02 de janeiro de 2017, houve um dos maiores massacress brasileiros, com duração de 17 horas deixando 56 mortos. Ficando atrás somente, do Massacre do Carandiru, ocorrido no Brasil em 2 de outubro de 1992 causando a morte de 111 detentos.

Em virtude desta rebelião ocorrida no Complexo Penitenciário Anísio Jobim - COMAPJ/AM, foi criado, por meio do Conselho Nacional de Justiça, através da portaria n 13 de 06 de março de 2017, o Grupo Especial de Monitoramento e Fiscalização - GMEF, tendo como objetivos: atuar nos limites das competências constitucionais do Conselho Nacional de Justiça CNJ e acompanhar as inspeções das unidades prisionais do Estado. As informações colhidas durante as visitas do GMEF indicaram que dentre os problemas enfrentados no sistema prisional estão: as péssimas condições de infraestrutura, a ineficiência da segurança nas prisões, falta de água para os detentos e a falta de comunicação.

No relatório que apurou a situação do sistema prisional no Amazonas, publicado em 2017, a então Presidente do Supremo Tribunal Federal - STF, ministra Cármen Lúcia, indicava que a cada detento no Sistema Prisional do Estado, são desembolsados em média $R \$ 4,9$ mil por mês, sendo o custo de cada detento no sistema prisional do Amazonas o mais caro do país. Ao compararmos o custo anual por aluno da Universidade Federal do Amazonas7, que custa em média $R \$ 15,736,86$, com o custo anual por detento do sistema prisional do Amazonas que custa anualmente $R \$ 58,800$, 00 , percebemos que a diferença é quase o triplo do custo gasto por aluno. Os dados explicitam a disparidade dos investimentos, por um lado o baixo

\footnotetext{
${ }^{5}$ Após o massacre ocorrido, o único local, dentro do Complexo penitenciário Anísio Jobim (COMPAJ), que não sofreu qualquer tipo de ataque foi o destinado ao funcionamento da escola.

6 Informação disponível em: http://www.cnj.jus.br/noticias/cnj/84466-grupo-do-cnjapresenta-primeiro-relato-sobre-situacao-carceraria-do-amazonas

7 Informação obtida por meio do Sistema Eletrônico do Serviço de Informação ao Cidadão e-SIC com o protocolo 23480. 027198/2018-56.
} 
investimento na educação e por outro a ineficiência do gasto com o sistema prisional.

\section{OS CAMINHOS METODOLÓGICOS DA PESQUISA}

Trata-se de um estudo documental no qual foram alisados, dados estatísticos, leis e documentos, fazendo-se também articulação com o procedimento metodológico do "estado da arte". Ao optar pelo "estado da arte" os pesquisadores são "[...] sustentados e movidos pelo desafio de conhecer o já construído e produzido para depois buscar o que ainda não foi feito". (Ferreira, 2002, p. 259). Conforme o mesmo autor, as fontes básicas para as pesquisas denominadas de estado da arte são os catálogos das mais variadas instituições educativas e órgão de fomento à pesquisa, com destaque para as associações nacionais e internacionais.

A natureza da pesquisa caracteriza-se como sendo quantiqualitativa, ou método misto, pois além de analisarmos dados, analisamos também as interpretações das realidades. Na visão de Minayo e Sanches (1993, p. 247) "O estudo quantitativo pode gerar questões para serem aprofundadas qualitativamente, e vice-versa".

As buscas pelas teses e dissertações foram realizadas no Sistema de Publicação Eletrônica de Teses e Dissertações (TEDE), que possibilitou o acesso ao catálogo das teses e dissertações produzidas e publicadas pelos pesquisadores das referidas universidades. Segundo Ferreira (2002):

Os catálogos permitem o rastreamento do já construído, orientam o leitor na pesquisa bibliográfica de produção de uma certa área. Eles podem ser consultados em ordem alfabética por assuntos, por temas, por autores, por datas, por áreas (FERREIRA, 2002, p. 261).

Com a finalidade de delimitar o rastreio das teses e dissertações, utilizamos na página de busca dos sistemas SISTEBIB/UFAM e SIB/UEA, Os termos: Sistema Prisional; Educação e Cárcere; Prisão e Privados de Liberdade. A partir dos resultados obtidos selecionamos as produções as quais faziam referência ao tema em estudo. 
Tivemos como ano de referência o período de 1991 a 2018, a escolha desse período se deu em virtude do recorte que abarca o ano de criação dos Programas de Pós-graduação da UFAM e UEA. A princípio tínhamos delimitado a busca somente para os programas de pós-graduação em Educação, mas em virtude do baixo quantitativo de produções resolvemos ampliar para os demais programas de pós-graduação do Estado contanto que evidenciassem a temática em estudo.

Durante o mapeamento foram localizadas 3 (três) dissertações e 1 (uma) tese no TEDE/UFAM, encontramos ainda 1 (uma) dissertação física que não estava no sistema da TEDE/UFAM, mas disponível (impressa) na Biblioteca Setorial do Setor Norte - UFAM, a identificação do trabalho ocorreu pelo acesso ao Catálogo de Defesas de Teses e Dissertações disponível no site do PPGE/UFAM. Com essa experiência constatamos que os 3 (três) Programas de Pós-graduação nos quais havíamos identificado as teses e dissertações, possuíam site, que disponibilizavam o catálogo das defesas de teses e dissertações. O que fez que adotássemos como critério para a pesquisa comparar os resultados obtidos nos sistemas das universidades, SISTEBIB/UFAM e SIB/UEA, com o catálogo de defesa de teses e dissertações disponibilizado pelos sites dos programas. A consulta adotada não identificou tese ou dissertação no TEDE/UEA sobre a temática Educação no Sistema Prisional. Assim, os programas de pós-graduação nos quais obtivemos resultados durante as buscas estão presentes na tabela abaixo:

Tabela 3. Programas com Teses e/ou Dissertações sobre o tema

\begin{tabular}{|l|l|}
\hline \multicolumn{1}{|c|}{ PROGRAMA } & \multicolumn{1}{|c|}{ INSTITUIÇÃO DE ENSINO } \\
\hline $\begin{array}{l}\text { Programa de Pós-graduação em Educação } \\
\text { - PPGE }\end{array}$ & $\begin{array}{l}\text { Faculdade de Educação da Universidade } \\
\text { Federal do Amazonas - FACED/UFAM }\end{array}$ \\
\hline $\begin{array}{l}\text { O Programa de Pós-graduação em } \\
\text { Sociologia-PPGS }\end{array}$ & $\begin{array}{l}\text { Instituto de Ciências Humanas e Letras } \\
\text { ICHL/UFAM (atualmente passou a ser } \\
\text { denominado de IFCHS Instituto de Filosofia, } \\
\text { Ciências Humanas e Sociais - IFCHS); }\end{array}$ \\
\hline $\begin{array}{l}\text { Programa de Pós-Graduação em Letras - } \\
\text { PPGL }\end{array}$ & Faculdade de Letras - FLET/UFAM \\
\hline
\end{tabular}


Fonte: elaborada pelas pesquisadoras.

Com a catalogação dos trabalhos, houve a necessidade de categorizar para uma análise e interpretação das informações. Assim, o trabalho agrupou as produções pela abordagem, procedimento, enfoque e resultados. Inicialmente o ponto básico para categorização e análise foi essencialmente a leitura dos resumos dos trabalhos, mas tendo em vista que:

"[...] nem todo resumo traz em si mesmo e de idêntica maneira todas as convenções previstas pelo gênero: em alguns falta a conclusão da pesquisa; em outros, falta o percurso metodológico, ainda em outros, pode ser encontrado um estilo mais narrativo (FERREIRA, 2002, p. 268)".

Diante disso, analisamos os trabalhos na íntegra, resultando na sistematização de um quadro, mas no intuito de tipificar a identidade da oferta educativa aos privados de liberdade no Amazonas, elaboramos um segundo quadro no qual analisamos a identidade da oferta educativa no sistema prisional do Estado a luz das perspectivas legais teóricas.

\section{ANÁLISE E DISCUSSÃO DOS RESULTADOS}

No TEDE/UFAM foram localizadas 3 (três) dissertações e 1 (uma) tese com referência ao tema em estudo. Encontramos ainda 1 (uma) dissertação física que não estava disponível no sistema de bibliotecas digital, mas que estava disponível (impressa) na Biblioteca Setorial do Setor Norte - UFAM, que identificamos pelo Catálogo de Defesas de Teses e Dissertações disponível no site do PPGE/UFAM. O quadro abaixo demonstra as Dissertações e Teses identificadas:

Quadro 1. Dissertações e tese identificadas

\begin{tabular}{|c|c|c|c|}
\hline Título & Autor (a) & Tipo & Ano \\
\hline
\end{tabular}




\begin{tabular}{|c|c|c|c|}
\hline Título & Autor (a) & Tipo & Ano \\
\hline $\begin{array}{l}1 \text { - A Educação de Jovens e } \\
\text { Adultos no Sistema Penitenciário } \\
\text { de Manaus: um estudo de caso } \\
\text { na Cadeiar Pública } \\
\text { Desembargador } \\
\text { Vidal Pessoa. }\end{array}$ & $\begin{array}{l}\text { Jhones Macário } \\
\text { da Silva } \\
\text { Muneymne }\end{array}$ & Dissertação & 2004 \\
\hline $\begin{array}{l}\text { 2. Educação nas prisões: } \\
\text { desafios e possibilidades do } \\
\text { ensino praticado nas unidades } \\
\text { prisionais de Manaus. }\end{array}$ & Alice Silva do Prado & Dissertação & 2015 \\
\hline $\begin{array}{l}\text { 3. Remição penal pela leitura e } \\
\text { letramento: subjetivação e } \\
\text { dessubjetivação do sujeito preso }\end{array}$ & $\begin{array}{l}\text { Thays Coelho de } \\
\text { Araújo }\end{array}$ & Dissertação & 2018 \\
\hline $\begin{array}{l}\text { 4. Políticas públicas e educação } \\
\text { para pessoas jovens e adultas } \\
\text { em situação de privação de } \\
\text { liberdade no Amazonas: } \\
\text { regulação da sociedade } \\
\text { antagonismos de direitos sociais. }\end{array}$ & $\begin{array}{c}\text { Emerson Sandro } \\
\text { Silva Saraiva }\end{array}$ & Tese & 2018 \\
\hline
\end{tabular}

Fonte: elaborado pelas pesquisadoras.

A abordagem metodológica que se destacou dentre as 3 dissertações foi a quantiqualitativa, apesar do autor da dissertação 1 (quadro I) não usar o termo "quantiqualitativa" mas indicar que a pesquisa é de cunho qualitativo e quantitativo. O que nos fez afirmar que na maioria das dissertações foi utilizada tanto a abordagem qualitativa como a quantitativa. Na única tese encontrada, o autor também utiliza a abordagem quantiqualitativa na sua pesquisa. Dentre os 4 (quatro) trabalhos 3 (três) apresentam abordagem quantiqualitativa. Sobre esse método - a utilização da abordagem qualitativa e quantitativa - denominado de quantiqualitativo, em Minayo e Sanches (1993), encontra-se o seguinte esclarecimento:

No entanto, se a relação entre quantitativo e qualitativo, entre objetividade e subjetividade não se reduz a um continuum, ela não pode ser pensada como oposição contraditória. Pelo contrário, é de se desejar que as relações sociais possam ser analisadas em seus aspectos mais "ecológicos" e "concretos" e aprofundadas em seus significados mais essenciais. Assim, o estudo quantitativo pode gerar 
questões para serem aprofundadas qualitativamente, e vice-versa (MINAYO; SANCHES, 1993, p. 247).

Em relação aos procedimentos metodológicos, nas três dissertações, os pesquisadores utilizaram o "estudo de caso" e a "pesquisa documental". $\mathrm{Na}$ tese identificada o pesquisador utilizou somente $\mathrm{O}$ procedimento documental em sua pesquisa. Com isso podemos afirmar que $100 \%$ dos pesquisadores utilizaram o procedimento metodológico documental em seus trabalhos.

No que diz respeito aos enfoques, a dissertação 1 e 3 utilizaram o enfoque do Materialismo - Histórico e Dialético, enquanto que a dissertação 2 se baseou na Sociologia Compreensiva. Em relação à tese, o pesquisador também utilizou o enfoque do Materialismo Histórico e Dialético. Conforme a comparação feita entre os trabalhos, percebe-se que o enfoque do Materialismo-Histórico-Dialético foi o mais utilizado. O Marxismo enquanto abordagem é caracterizado por Minayo (2015) por considerar: [...] a historicidade dos processos sociais e dos conceitos, as condições socioeconômicas de produção dos fenômenos e as contradições sociais é uma outra teoria sociológica importante. (Minayo, 2015, p. 24).

Conforme destacado, a abordagem metodológica mais utilizada nos trabalhos foi a quantiqualitativa, articulando-se com 0 enfoque do Materialismo-Histórico-Dialético. Para explicar esse fato recorremos a Minayo (2015) no qual afirma que:

A dialética trabalha com a valorização das quantidades e da qualidade, com as contradições intrínsecas às ações e realizações humanas, e com o movimento perene entre parte e todo e interioridade e exterioridade dos fenômenos (MINAYO, 2015, p. 24).

Para melhor visualizar, os quadros elaborados apresentam uma síntese do foi que comparado a partir dos resumos e demais elementos das produções encontradas.

Quadro 2. Categorização das dissertações e tese

\begin{tabular}{|l|l|l|l|l}
\hline Dissertações & Abordagem & Procedimento & Enfoque & Resultados
\end{tabular}




\begin{tabular}{|c|c|c|c|c|}
\hline Dissertações & Abordagem & Procedimento & Enfoque & Resultados \\
\hline 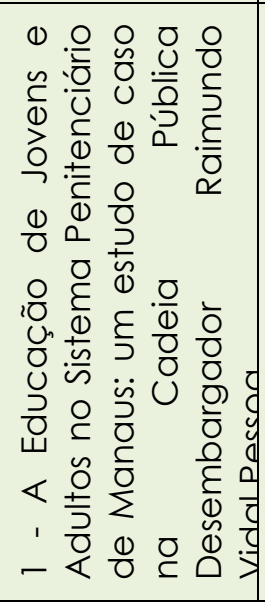 & $\begin{array}{c}\text { Quantitativa } \\
e \\
\text { Qualitativa }\end{array}$ & $\begin{array}{l}\text { Estudo de Caso } \\
\text { Documental }\end{array}$ & $\begin{array}{l}\text { Materialismo- } \\
\text { histórico- } \\
\text { dialético }\end{array}$ & $\begin{array}{l}\text { "[...] a crença otimista da } \\
\text { professora em relação ao seu } \\
\text { trabalho e a aceitação dócil } \\
\text { do aluno, em relação aos } \\
\text { seus insucessos, como sendo } \\
\text { um problema pessoal, uma } \\
\text { incapacidade individual, } \\
\text { enfim a repetição histórica } \\
\text { dessa inculcação ideológica } \\
\text { perversa, ou seja a absorção } \\
\text { por parte desse tipo de aluno, } \\
\text { da culpabilidade de seu } \\
\text { estado de ser analfabeto." } \\
\text { (Muneymne, 2004, p. 176) }\end{array}$ \\
\hline 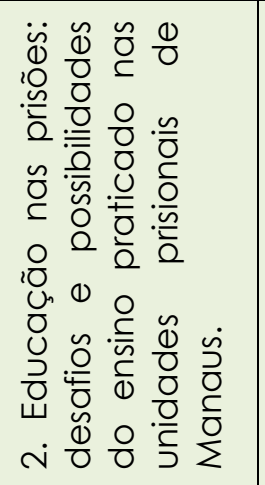 & $\begin{array}{l}\text { Quanti/quali } \\
\text { tativa }\end{array}$ & $\begin{array}{l}\text { Estudo de Caso } \\
\text { Documental }\end{array}$ & $\begin{array}{c}\text { Sociologia } \\
\text { compreensi } \\
\text { va }\end{array}$ & $\begin{array}{l}\text { "[...] os relatos apresentados } \\
\text { nos revelam que os internos } \\
\text { enxergam nas práticas de } \\
\text { ensino como uma } \\
\text { possibilidade de reduzir o } \\
\text { tempo de sua sentença e, ao } \\
\text { mesmo tempo, de obter o } \\
\text { aprendizado escolar cujo } \\
\text { acesso não foi possível } \\
\text { anteriormente". (Prado, 2015, } \\
\text { p.92). }\end{array}$ \\
\hline 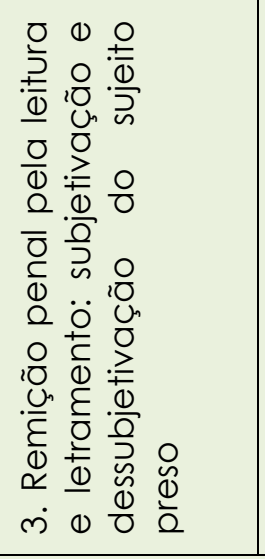 & Qualitativa & $\begin{array}{l}\text { Estudo de Caso } \\
\text { Documental }\end{array}$ & $\begin{array}{l}\text { Materialism } \\
\text { o-histórico }\end{array}$ & $\begin{array}{l}\text { A compreensão produzida } \\
\text { pela análise dos dados } \\
\text { permite afirmar que se for } \\
\text { pensado em um âmbito } \\
\text { maior, o Projeto de Remição } \\
\text { de Pena pela Leitura Encontro } \\
\text { Com a Leitura - Ler Liberta } \\
\text { está associado a táticas de } \\
\text { dessubjetivação, pois para } \\
\text { que o sujeito volte a ser sujeito } \\
\text { social, é necessário que ele } \\
\text { passe por anulações do "eu" } \\
\text { (Araújo, 2018, p. 8). }\end{array}$ \\
\hline
\end{tabular}

Fonte: elaborado pelas pesquisadoras.

Quadro 3. Categorização da tese identificada no TEDE/UFAM

\begin{tabular}{|c|c|c|c|c|}
\hline Tese & Abordagem & Procedimento & Enfoque & Resultados \\
\hline
\end{tabular}




\begin{tabular}{|c|c|c|c|c|}
\hline 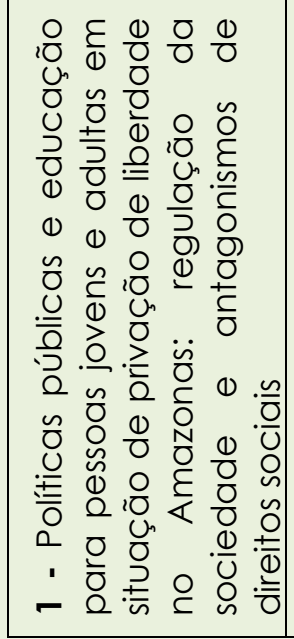 & $\begin{array}{c}\text { Quantiquali } \\
\text { tativa }\end{array}$ & $\begin{array}{c}\text { Pesquisa } \\
\text { Documental }\end{array}$ & $\begin{array}{l}\text { Histórico- } \\
\text { dialético }\end{array}$ & $\begin{array}{l}\text { Os jovens e adultos } \\
\text { privados de liberdade no } \\
\text { Amazonas, enquanto } \\
\text { sujeitos Amazônicos, } \\
\text { tornam-se fragmentados } \\
\text { e despejados de sua } \\
\text { condição de sujeitos, } \\
\text { sendo revestidos da } \\
\text { condição de indivíduos, } \\
\text { para os quais o direito à } \\
\text { educação e à liberdade } \\
\text { são camuflados por } \\
\text { políticas de inclusão } \\
\text { social (Saraiva, 2018, } \\
\text { p.8). }\end{array}$ \\
\hline
\end{tabular}

Fonte: elaborado pelas pesquisadoras.

Os resultados demonstram que, na dissertação 1, os estudantes aceitam a condição de serem analfabetos e afirmam que esta condição se deu por conta de sua incapacidade. No entanto Mayer (2013, p. 35) alega que "a maior parte dos detentos é constituída por pobres, tem um nível educacional muito baixo, jamais conheceram a escola ou, quando conheceram, sua experiência frequentemente terminou em fracasso". Apesar da Constituição Federal determinar, no artigo 205, a educação como um direito de todos e dever do Estado, percebe-se que ainda existe parcela da população sem ter acesso. Como descrito por Cacicedo (2016, p. 123):

Um dos fatores que contribui para o quadro social desigual que caracteriza a sociedade brasileira, e, ao mesmo tempo, decorre dessa situação de desigualdade, é a falta de acesso à educação por grande parcela da população.

Na dissertação 2 é relatado que os estudantes privados de liberdade identificam as práticas de ensino como uma possibilidade de reduzir o tempo de sua sentença, reconhecem também, que é uma possibilidade para obter o aprendizado que não tiveram acesso. Com relação a essa possibilidade de remir parte do tempo de execução da pena por estudo ou por trabalho, Julião (2018) afirma, que por demandar menos recurso, teme que a proposta venha a ser utilizada equivocadamente. $O$ autor também 
alerta, que a proposta possa ser usada como estratégia política para se propagar a remição como sendo um benefício para o privado de liberdade, o que subtrairia um direito fundamental, que é a Educação.

Na dissertação 3 a pesquisadora afirma que o Projeto de Remição de Pena pela Leitura desenvolvido na Unidade Prisional Semiaberto Feminino UPSF, em Manaus/AM, intitulado "Encontro Com a Leitura - Ler Liberta": está associado a táticas de dessubjetivação, pois para que o sujeito volte a ser sujeito social, é necessário que ele passe por anulações do "eu". (Araújo, 2018, p. 8).

O Plano Nacional de Educação em Direitos Humanos (PNEDH, 2006, p. 34) estabelece, como ação programática, programas educativos, nos estabelecimentos penais, com o objetivo de assegurar os processos de formação na perspectiva crítica dos direitos humanos. Porém, ao analisar a dissertação 3, percebemos que a perspectiva crítica dos direitos humanos não está sendo colocada em prática. Sobre a desconsideração da subjetividade do sujeito, Cacicedo (2016) utiliza-se da seguinte argumentação:

A prisão molda as pessoas a ela submetidas por meio de uma
sujeição à lógica prisional, de modo a empreender um amplo
controle sobre seu comportamento. Referida lógica prisional
disciplinar com seus corolários de ordem, segurança e autoridade
caminha no sentido de retirar do sujeito preso sua autonomia, e com
a desconsideração de sua subjetividade impõe a obediência como
verdadeira estratégia de sobrevivência (CACICEDO, 2016, p.126).

Ainda segundo o referido autor, o viés disciplinador constitui-se como um dos obstáculos e desafios para a implementação da educação nas prisões.

Na tese 1, identificada no TEDE/UFAM, há semelhanças com o descrito na dissertação 3 quanto à perda da autonomia e da subjetividade do privado de liberdade. Saraiva (2018), em sua tese, afirma que os jovens privados de liberdade no Amazonas são despejados de sua condição de sujeitos no qual o direito à educação e à liberdade são mascarados por 
políticas de inclusão social. Enquanto isso a Lei de Diretrizes e Bases da Educação determina, no artigo $5^{\circ}$ que:

O acesso à educação básica obrigatória é direito público subjetivo, podendo qualquer cidadão, grupo de cidadãos, associação comunitária, organização sindical, entidade de classe ou outra legalmente constituída e, ainda, o Ministério Público, acionar o poder público para exigi-lo (BRASIL, 1996).

Percebe-se certo "esquivamento" por parte dos Estados quanto a oferta educativa aos privados de liberdade, pois a oferta ocorre via de regra por projetos isolados. Julião (2016, p. 28) afirma que é esperado que os estados "[...] assumam a política de educação aos Privados de Liberdade não como uma ação pontual, isolada, mas sim como uma política pública de educação". A educação não pode ser parte do processo da pena, mas um direito em si.

A partir das discussões apresentadas pelos resultados das produções científicas identificadas no TEDE/UFAM percebeu-se que a oferta da educação acontece vinculada à pena e não como um direito em si, as ações seguem o descrito na maioria da literatura especializada (De Maeyer, 2013; Julião, 2016), com ações isoladas mascaradas de educação. Há um contraste entre a previsão legal e as práticas ofertadas e mais ainda um contexto brutal de ausências de direitos. Cacicedo $(2016$, p. 127) afirma que no contexto contemporâneo "[...] a maior violação de direitos humanos no Brasil é representada pelo sistema penitenciário nacional". A oferta educativa no sistema prisional do Estado apresentou-se ainda, como camuflada por políticas de inclusão, onde os privados de liberdade são despojados da condição de sujeitos no qual seus direitos básicos, como a educação, são negados.

Em síntese é possível afirmar que a tipificação da oferta educativa no sistema prisional do Amazonas apresenta sua identidade amparada em perspectivas legais e teóricas com pouca ou nenhuma distinção dos demais cenários nacionais. O quadro abaixo busca efetivar essa identidade constituída a partir das dissertações, tese e fundamentos aqui discutidos. 
Quadro 4. Síntese da Análise dos Resultados

\begin{tabular}{|c|c|c|}
\hline $\begin{array}{l}\text { A IDENTIDADE DA } \\
\text { EDUCAÇÃO }\end{array}$ & PERSPECTIVAS LEGAIS & PERSPECTIVAS TEÓRICAS \\
\hline $\begin{array}{l}\text { "[...] aceitação dócil do } \\
\text { aluno, em relação aos seus } \\
\text { insucessos, como sendo um } \\
\text { problema pessoal, uma } \\
\text { incapacidade individual, } \\
\text { enfim a repetição histórica } \\
\text { dessa inculcação ideológica } \\
\text { perversa, ou seja, a } \\
\text { absorção por parte desse } \\
\text { tipo de aluno, da } \\
\text { culpabilidade de seu estado } \\
\text { de ser analfabeto. } \\
\text { (Muneymne, 2004, p. 176)". }\end{array}$ & $\begin{array}{l}\text { "A educação, direito de } \\
\text { todos e dever do Estado e } \\
\text { da família, será promovida e } \\
\text { incentivada com a } \\
\text { colaboração da sociedade, } \\
\text { visando ao pleno } \\
\text { desenvolvimento da pessoa, } \\
\text { seu preparo para o exercício } \\
\text { da cidadania e sua } \\
\text { qualificação para o trabalho } \\
\text { (CF, 1988)". }\end{array}$ & $\begin{array}{l}\text { "A maior parte dos detentos } \\
\text { é constituída por pobres, } \\
\text { tem um nível educacional } \\
\text { muito baixo, jamais } \\
\text { conheceram a escola ou, } \\
\text { quando conheceram, sua } \\
\text { experiência frequentemente } \\
\text { terminou em fracasso: muitos } \\
\text { detentos são jovens ainda e, } \\
\text { em numerosos países, os } \\
\text { migrantes (econômicos) } \\
\text { constituem uma parte } \\
\text { importante da população } \\
\text { carcerária (Mayer, 2013, } \\
\text { p.35)". }\end{array}$ \\
\hline $\begin{array}{l}\text { "[...] os relatos apresentados } \\
\text { nos revelam que os internos } \\
\text { enxergam nas práticas de } \\
\text { ensino como uma } \\
\text { possibilidade de reduzir o } \\
\text { tempo de sua sentença e, } \\
\text { ao mesmo tempo, de obter } \\
\text { o aprendizado escolar cujo } \\
\text { acesso não foi possível } \\
\text { anteriormente (Prado, 2015, } \\
\text { p.92)". }\end{array}$ & $\begin{array}{l}\text { "O condenado que cumpre } \\
\text { a pena em regime fechado } \\
\text { ou semiaberto poderá remir, } \\
\text { por trabalho ou por estudo, } \\
\text { parte do tempo de } \\
\text { execução da pena (LEP, } \\
2011 \text { )". }\end{array}$ & $\begin{array}{l}\text { "Quanto a remição pela } \\
\text { leitura, por demandar menos } \\
\text { recurso temo que a proposta } \\
\text { venha ser utilizada } \\
\text { equivocadamente, sendo o } \\
\text { projeto de experiências de } \\
\text { escolarização no ambiente } \\
\text { prisional. Sendo literalmente } \\
\text { propagado como um } \\
\text { benefício para o apenado, } \\
\text { a proposta pode encobrir } \\
\text { uma estratégia política que, } \\
\text { ao contrário, subtrai direitos } \\
\text { (Julião, 2018, p. 184)". }\end{array}$ \\
\hline $\begin{array}{l}\text { "A compreensão produzida } \\
\text { pela análise dos dados } \\
\text { permite afirmar que se for } \\
\text { pensado em um âmbito } \\
\text { maior, o Projeto de Remição } \\
\text { de Pena pela Leitura } \\
\text { Encontro Com a Leitura - Ler } \\
\text { Liberta está associado à } \\
\text { táticas de dessubjetivação, } \\
\text { pois para que o sujeito volte } \\
\text { a ser sujeito social, é } \\
\text { necessário que ele passe por } \\
\text { anulações do "eu". Isso } \\
\text { ocorre em decorrência das } \\
\text { atividades de estudo na } \\
\text { prisão que visam resgatar a } \\
\text { obediência do sujeito, } \\
\text { remetendo a estratégias de } \\
\text { (re) produção de corpos } \\
\text { dóceis ao poder. (Araújo, } \\
2018, \text { p. 8)". }\end{array}$ & $\begin{array}{l}\text { "20. promover e garantir a } \\
\text { elaboração e a } \\
\text { implementação de } \\
\text { programas educativos que } \\
\text { assegurem, no sistema } \\
\text { penitenciário, processos de } \\
\text { formação na perspectiva } \\
\text { crítica dos direitos humanos, } \\
\text { com a inclusão de } \\
\text { atividades profissionalizantes, } \\
\text { artísticas, esportivas e de } \\
\text { lazer para a população } \\
\text { prisional (PNEDH, 2006, p. } \\
\text { 34)". }\end{array}$ & $\begin{array}{l}\text { "A prisão molda as pessoas } \\
\text { a ela submetidas por meio } \\
\text { de uma sujeição à lógica } \\
\text { prisional, de modo a } \\
\text { empreender um amplo } \\
\text { controle sobre seu } \\
\text { comportamento. Referida } \\
\text { lógica prisional disciplinar } \\
\text { com seus corolários de } \\
\text { ordem, segurança e } \\
\text { autoridade caminha no } \\
\text { sentido de retirar do sujeito } \\
\text { preso sua autonomia, e com } \\
\text { a desconsideração de sua } \\
\text { subjetividade impõe a } \\
\text { obediência vala como } \\
\text { verdadeira estratégia de } \\
\text { sobrevivência. (Cacicedo, } \\
\text { 2016, p.126)". }\end{array}$ \\
\hline jovens & acesso & "Espera-se que os estados, \\
\hline
\end{tabular}




\begin{tabular}{|c|c|c|}
\hline $\begin{array}{l}\text { A IDENTIDADE DA } \\
\text { EDUCAÇÃO }\end{array}$ & PERSPECTIVAS LEGAIS & PERSPECTIVAS TEÓRICAS \\
\hline $\begin{array}{l}\text { privados de liberdade no } \\
\text { Amazonas, enquanto sujeitos } \\
\text { Amazônicos tornam-se } \\
\text { fragmentados e despejados } \\
\text { de sua condição de sujeitos, } \\
\text { sendo revestidos da } \\
\text { condição de indivíduos, } \\
\text { para os quais o direito à } \\
\text { educação e à liberdade são } \\
\text { camuflados por políticas de } \\
\text { inclusão social (Saraiva, 201, } \\
\text { p.8)". }\end{array}$ & $\begin{array}{l}\text { educação } \\
\text { obrigatória é direito pública } \\
\text { subjetivo, podendo qualquer } \\
\text { cidadão, grupo de } \\
\text { cidadãos, associação } \\
\text { comunitária, organização } \\
\text { sindical, entidade de classe } \\
\text { ou outra legalmente } \\
\text { constituída e, ainda, o } \\
\text { Ministério Público, acionar o } \\
\text { poder público para exigi-lo } \\
\text { (LDB, 1996)". }\end{array}$ & $\begin{array}{l}\text { através das suas secretarias } \\
\text { estaduais de educação, } \\
\text { assumam a política de } \\
\text { educação para jovens e } \\
\text { adultos em situação de } \\
\text { privação de liberdade, } \\
\text { reconhecendo-a não mais } \\
\text { como uma ação pontual, } \\
\text { isolada, voluntária, mas sim } \\
\text { como uma política pública } \\
\text { de educação (Julião, 2016, } \\
\text { p.28)". }\end{array}$ \\
\hline
\end{tabular}

Fonte: elaborado pelas pesquisadoras.

\section{CONSIDERAÇÕES FINAIS}

Os dispositivos legais asseguram a educação como um direito inerente a todo ser humano sem distinção. Os referenciais teóricos embasam discussões que reiteram esses direitos e nos ajudam a analisar e compreender as "correntezas" que os mesmos enfrentam para serem efetivados.

Durante a pesquisa percebemos que houve um aumento na produção científica sobre a oferta educativa aos privados de liberdade, mas que ainda existe uma espécie de silenciamento, pois são tímidas as discussões sobre a temática, tanto na oferta quanto na prática educativa. Apesar de identificarmos 4 (quatro) trabalhos nos programas de pósgraduação do Amazonas, percebemos que o quantitativo é baixo diante da trajetória de 90 anos da implementação de escolas dentro dos presídios da capital e do interior do Estado.

As produções científicas analisadas indicam os processos da oferta educativa aos privados de liberdade do Amazonas, caracterizada como um direito esvaziado pela manutenção de concepções que vinculam a educação ao cumprimento da pena ou a uma espécie de benevolência do Estado em relação à garantia de condições para o exercício desse direito. As ações educativas ofertadas no sistema prisional se resumem a ações 
isoladas, mascaradas de oferta educativa configurando uma subtração de direitos.

A oferta educativa aos privados de liberdade ainda encontra muitos entraves para ser efetivada. Acreditamos que é necessário fomentar discussões nos espaços acadêmicos, políticos, religiosos e nos diferentes contextos, a fim de que se direcionem as políticas e ações para que o direito à oferta educativa aos privados de liberdade seja efetivado.

Utilizamos aqui as palavras de Paulo Freire $(1981$, p.73) ao afirmar que "Seria na verdade uma atitude ingênua esperar que as classes dominantes desenvolvessem uma forma de educação que proporcionasse às classes dominadas perceber as injustiças sociais de maneira crítica". Percebemos que vivendo em meio a um sistema que impossibilita a igualdade de direitos precisamos todos os dias "remar contra a correnteza" para garantir direitos sobretudo, aos pobres e excluídos.

\section{REFERÊNCIAS}

AMAZONAS. Secretaria de Estado da Educação e Qualidade do Ensino SEDUC. Plano Estadual de Educação nas Prisões. Manaus, 2012.

ARAÚJO, T. C. de. Remição Penal pela Leitura e Letramento: subjetivação e dessubjetivação do sujeito preso. 2018. 133f. Dissertação (Mestrado em Letras) - Programa de Pós-graduação em Letras, Universidade Federal do Amazonas, Manaus, 2018. Disponível em: https://tede.ufam.edu.br/handle/tede/6549. Acesso em: 21 nov. 2018.

BRASIL. [Constituição (1988)]. Constituição da República Federativa do Brasil de 1998. Diário Oficial da União, Brasília, 1988. Disponível em: http://www.planalto.gov.br/ccivil_03/constituicao/constituicaocompilado.ht m. Acesso em: 21 nov. 2018.

BRASIL. Lei n 7.210, de 11 de julho de 1984. Institui a Lei de Execução Penal. Diário Oficial da União, Brasília, 1984. Disponível em: http://www.planalto.gov.br/ccivil_03/LEIS/L7210.htm. Acesso em: 21 nov. 2018.

BRASIL. Lei no 12.433, de 29 de junho de 2011 . Altera a Lei no 7.210, de 11 de julho de 1984 (Lei de Execução Penal), para dispor sobre a remição de parte do tempo de execução da pena por estudo ou por trabalho. Diário Oficial 
da União, Brasília, 2011. Disponível em: http://www.planalto.gov.br/ccivil_03/_ato2011-2014/2011/lei/l12433.htm. Acesso em: 21 nov. 2018.

BRASIL. Lei $n^{\circ}$ 13.163, de 9 de setembro de 2015. Modifica a Lei no 7.210, de 11 de julho de 1984 - Lei de Execução Penal, para instituir o ensino médio nas penitenciárias. Diário Oficial da União, Brasília, 2015. Disponível em:

http://www.planalto.gov.br/ccivil_03/_Ato2015-2018/2015/Lei/L13163.htm. Acesso em: 21 nov. 2018.

BRASIL. Lei n 9394, de 20 de dezembro de 1996. Estabelece as diretrizes e bases da educação nacional. Diário Oficial da União, Brasília, 1996.

Disponível em: http://www.planalto.gov.br/ccivil_03/LEIS/L9394.htm. Acesso em: 21 nov. 2018.

BRASIL. Resolução CNE/CEB n 02/2010, de 19 de maio de 2010. Dispõe sobre as Diretrizes Nacionais para a oferta de educação para jovens e adultos em situação de privação de liberdade nos estabelecimentos penais. Diário Oficial da União, Brasília, 2010. Disponível em:

http://portal.mec.gov.br/index.php? option=com_docman\&view=download \&alias=51 42-rceb002-10\&category_slug=maio-2010-pdf\&ltemid=30192. Acesso: 21 nov. 2018.

BRASIL. Decreto n' 7.626/2011, de 24 de novembro e 2011. Institui o Plano Estratégico de Educação no Âmbito do Sistema Prisional - PEESP. Diário Oficial da União, Brasília, 2011. Disponível em: http://www.planalto.gov.br/ccivil_03/_ato20112014/2011/decreto/d7626.htm. Acesso em: 21 nov. 2018.

BRASIL. Secretaria Especial dos Direitos Humanos. Plano Nacional de Educação em Direitos Humanos. Brasília: 2007. Disponível em: http://portal.mec.gov.br/index.php? option=com_docman\&view=download \&alias=2191-plano-nacional-pdf\&ltemid=30192. Acesso em: 11 dez. 2018.

BRASIL. Conselho Nacional de Justiça. Banco Nacional de Monitoramento de Prisões - BNMP 2.0 Cadastro Nacional de Presos, Brasília: 2018. Disponível em: http://www.cnj.jus.br/files/conteudo/arquivo/2018/08/987409aa856db291197 e81ed314499fb.pdf. Acesso em: 22 nov. 2018.

CACICEDO, P. Desafios para a educação nas prisões na era do grande encarceramento. Aracê - Direitos Humanos em Revista, [s.l.], Associação Nacional de Direitos Humanos, Pesquisa e Pós-Graduação, v. 3, n. 4, p. 122138, fev. 2016. Disponível em:

https://arace.emnuvens.com.br/arace/article/view/105. Acesso em: 21 nov. 2018. 
DE MAEYER, M. A Educação na Prisão não é uma Mera Atividade. Educação e Realidade, Porto Alegre, Universidade Federal do Rio Grande do Sul. v.38, n.1, p. 33-49, jan./mar. 2013. Disponível em: htpp://www.ufrgs.br/edu_realidade. Acesso em: 21 nov. 2018.

ESTEVES, M. Análise de conteúdo. In: LIMA, J. Á. de; PACHECO, J. A. Fazer Investigação: contributos para a elaboração de dissertações e teses. Porto (Portugal): Editora Porto, 2006. p. 105-126.

FERREIRA, N. S. de A. As pesquisas Denominadas "Estado da Arte". Educação \& Sociedade, Campinas, Universidade Estadual de Campinas, v. 23, n. 79, p. 257-272, ago.2002.

FERREIRA, C. L. L.; VALOIS, L. C. Sistema Penitenciário do Amazonas: História Evolução - Contexto Atual. Curitiba: Juruá, 2009.

FREIRE, P. Ação cultural para a liberdade. Rio de Janeiro: Paz e Terra, 1981.

FOUCAULT, M. Vigiar e Punir: o nascimento da prisão. Petrópolis (RJ): Vozes, 2009.

GARCIA, F. M.; ARAúJO, T. C. de; SANTOS, P. M. dos. Processos, peculiaridades e prática docente na oferta educativa no sistema prisional do Amazonas. Revista Práxis Educacional, Bahia, v.14, n. 28, p. 197-224, abr./jun. 2018.

JULIÃO, E. F. Escola na ou da prisão? Cadernos Cedes, Campinas, v.36, n.98, p. 25-42, jan./abr, 2016. Disponível em:

http://www.scielo.br/pdf/ccedes/v36n98/1678-71 10-ccedes-36-98-00025.pdf. Acesso em: 21 nov. 2018.

JULIÃO, E. F. Panorama da Política Nacional de Educação para Jovens e Adultos em Situação de Restrição e Privação de Liberdade no Brasil. In: JULIÃO, E. F.(org). Políticas de Educação nas Prisões da América do Sul: questões, perspectivas e desafios. Jundiaí (SP): Paco editorial, 2018.

MARX, K. O Dezoito Brumário de Louis Bonaparte. São Paulo: Centauro, 2006.

MINAYO, M. C. de S. O Desafio da Pesquisa Social. In: MINAYO, M. C. de S. (org). Pesquisa Social: teoria, método e criatividade. Petrópolis (RJ): Vozes, 2015. p.09-29.

MINAYO, M. C. de S.; SANCHES, O. Quantitativo-qualitativo: oposição ou complementaridade? Caderno de Saúde Pública, Rio de Janeiro, v. 9, n. 3, p. 239-262, jul./set, 1993. 
MUNEYMNE, J. M. da S. A educação de Jovens e Adultos no Sistema

Penitenciário de Manaus: estudo de caso na cadeia pública

desembargador Raimundo Vidal Pessoa. 2004. 177f. Dissertação (Mestrado em Educação) - Programa e Pós-graduação em Educação, Universidade Federal do Amazonas. Manaus, 2004.

ONU. Assembleia Geral das Nações Unidas em Paris. Declaração Universal dos Direitos Humanos (DUDH), 1948. Disponível em:

<https://nacoesunidas.org/direitoshumanos/declaracao>/. Acesso em: 21 nov. 2018.

PRADO, A. S. do. Educação nas Prisões: desafios e possibilidades do ensino praticado nas unidades prisionais de Manaus. 2015. 107f. Dissertação (Mestrado em Sociologia) - Programa de Pós-graduação em Sociologia, Universidade Federal do Amazonas. Manaus, 2015. Disponível em: https://tede.ufam.edu.br/handle/tede/5521. Acesso em: 21 nov. 2018.

SARAIVA, E. S. S. Políticas Públicas e Educação para Pessoas Jovens e Adultas em Situação de Privação de Liberdade no Amazonas: regulação da sociedade e antagonismos de direitos sociais. 2018. 347f. Tese (Doutorado em Educação) - Programa de Pós-graduação em Educação, Universidade Federal do Amazonas. Manaus, 2018. Disponível em:

https://tede.ufam.edu.br/handle/tede/6516. Acesso em: 21 nov. 2018.

VALOIS, L. C. Ressocialização versus legalidade: em prol de uma possível comunicação na execução penal. Novas Demandas Sociais, Velhas (e demagógicas) Soluções. Instituto Brasileiro de Ciências Criminais, São Paulo, v.21, n. 250, p. 10-12, set. 2013. Disponível em:

https://www.ibccrim.org.br/boletim_artigos/291-250-setembro2013. Acesso em: 21 nov. 2018.

Recebido em: 15 de setembro de 2018 Aprovado em: 15 de maio de 2019 